\title{
Farklı Oranlardaki Zeytin Posası-Mısır Hasılı Karışımlarının Silaj Kalitesinin Belirlenmesi
}

\author{
Asuman Arslan Duru ${ }^{1 *}$, Şerafettin Kaya ${ }^{2}$ \\ ${ }^{1}$ Ușak Üniversitesi, Ziraat ve Doğa Bilimleri Fakültesi, Zootekni Bölümü, 64200 Ușak, Türkiye \\ ${ }^{2}$ Mustafa Kemal Üniversitesi, Ziraat Fakültesi, Zootekni Bölümü, 31034 Hatay, Türkiye

\section{A K A L E B İ L G İ S I} \\ Ö Z E T
}

Geliş 07 Ekim 2016

Kabul 08 Kasim 2016

Çevrimiçi baskı, ISSN: 2148-127X

Anahtar Kelimeler:

Zeytin posası

Silaj

Misir hasilı

In vitro sindirilebilirlik

Aerobik stabilite

*Sorumlu Yazar:

E-mail: asuman.duru@usak.edu.tr
Bu çalışmada, laboratuvar koşullarında zeytinyağı sanayii yan ürünü yaş zeytin posasının mısır hasılına farklı oranlarda ilave edilmesiyle oluşturulan silajların, ham besin madde içerikleri, fermentasyon özellikleri ve in vitro sindirilebilirlikleri üzerine etkilerinin belirlenmesi amaçlanmıştır. Araştırmada kullanılan zeytin posası, mısır hasılına \%0 (kontrol), 20 ve 40 düzeylerinde ilave edilmiş ve silolama dönemi 56 gün devam etmiştir. Silolama dönemi sonunda, mısır hasılına zeytin posası ilave edilen silajlarda kuru madde, organik madde, ham yağ, asit deterjan fiber, asit deterjan lignin içerikleri önemli düzeyde artmış ancak zeytin posası ilaveli silajların ham protein içeriği azalmıştır . En yüksek ham selüloz değeri $\% 40$ zeytin posası ilave edilen silajlarda saptanmıştır. Ham kül, laktik asit, asetik asit, $\mathrm{pH}$ ve $\mathrm{CO}_{2}$ içerikleri bakımından silaj grupları arasında görülen farklılıklar istatistiki olarak önemli bulunmamıştır. Silaj gruplarında bütirik asit ve amonyak azotuna rastlanmazken; zeytin posası ilave edilen gruplarda propiyonik aside de rastlanmamıştır. Misir hasılına zeytin posas ilave edilen gruplarda in vitro organik madde, kuru madde ve nötral deterjan fiber sindirilebilirliği artmıştır. Sonuç olarak, zeytinyağı sanayii yan ürünü olan zeytin posasının kaliteli sayılabilecek bir silo yemi olabileceği sonucuna varılmıştır. Özellikle mısır hasılına \%40 zeytin posası ilave edilerek oluşturulan silajlardan gerek fiziksel ve gerekse kimyasal özellikleri bakımından memnuniyet verici sonuçlar elde edilmiştir.

Turkish Journal Of Agriculture - Food Science And Technology, 4(12): 1201-1206, 2016

\section{Determination of Silage Quality of Olive Cake and Corn Mixtures in Different Ratios}

\section{A R T I C LE INFO}

Article history:

Received 07 October 2016

Accepted 08 November 2016

Available online, ISSN: $2148-127 \mathrm{X}$

Keywords:

Fresh olive cake

Silage

Corn

In vitro digestibility

Aerobic stability

*Corresponding Author:

E-mail: asuman.duru@usak.edu.tr
A B S T R A C T

In this study, corn silage with different ratios of by adding olive pomace olive industry by-product under laboratory conditions was aimed to determine the effects on nutrient contents, fermentation characteristics and in vitro digestibility. Olive pomace used in the research, was added in $0 \%$ (control), 20 and 40 levels in corn silage and ensiling period continued during 56 days. At the end of the ensiling period, differences seen in terms of dry matter content, organic matter, crude fat, acit detergent fiber, acid detergent lignin, in each level consisting of corn silage is added to olive pomace were found significant but the crude protein content of the olive pomace-added silages decreased. The highest crude fiber value was determined in the silages added with $40 \%$ olive pomace. Crude ash, lactic acid, acetic acid, $\mathrm{pH}$ and $\mathrm{CO}_{2}$ differences seen in terms of rates were not found significant. Propoionic acid wasn't found in the groups to which olive pomace was added, while butyric acid and ammonia nitrogen weren't observed in all silage groups in the study. At the same time, in vitro organic matter, dry matter and neutral detergent fiber digestibility of silages increased in each level consisting of corn silage is added to olive pomace. As a result, it was considered result that olive pomace the oil industry by product can be a silo feed quality. In particular, the corns by adding $40 \%$ of the olive pomace made silage were obtained satisfactory results in terms of both physical and chemical properties. 


\section{Giriş}

Ülkemizde silajlık yem bitkisi olarak genellikle misır kullanılmakta olup, alternatif kaba yem kaynaklarından örneğin, kışlık buğday, çayır otu, gıda sanayi yan ürünleri (posalar vb.) gibi silolanmaya uygun diğer ürünlerden yeterince yararlanılamamaktadır (Ö̈zen ve ark., 2005). Yapılan çalışmalar sonucunda bu kaynakların yem girdi maliyetlerini düşürerek karlılığ 1 arttırdığı yönündeki bildirişler, çiftlik hayvanlarının beslenmesinde alternatif yem kaynaklarının önemini bir kez daha ortaya koymaktadır. Bu bağlamda, zeytinyağı üretimi sonrasında elde edilen bir yan ürün olan zeytin posası, ruminant beslemede kullanılabilecek önemli bir alternatif yem kaynağı olarak görülmektedir. (Filya ve ark., 2006).

Zeytin posası gerek yağ gerekse protein kaynağı olması nedeniyle ülkemiz için önemli bir alternatif yem maddesi olarak öne çıkmaktadır (Keser ve Bilal, 2010). Kısa sürede fazla miktarda elde edilen yaş zeytin posasının ruminant beslemede kullanılabilirliğinin artırılması için saklama koşullarının iyileştirilmesi ve besleme değerinin yükseltilmesi gerekmektedir. Bu amaçla, zeytin posasının tek başına veya diğer hammaddelerle silolanması ile besleme değerinin iyileştirilmesi ve ruminant beslemede kullanılabilirliğinin artııılmasına yönelik çalışmalar yapılmaktadır.

Zeytin posasının silaj olarak tek başına (Hadjipanayiotou, 1999) veya tavuk gübresi (Nefzaoui, 1991), üre (Al-Jassim ve ark., 1997), melas (Weinberg ve ark., 2008) veya alkaliler (Nefzaoui ve Vanbelle, 1986) veya formik asit, üre ve melas kombinasyonu ile birlikte silolandığında ekonomik olarak saklanabildiği ve zeytin posasının içerdiği polifenollerin silolama ile azaldığı ve böylece bu yan ürünün yem değerinin arttığını bildiren çalışmalar mevcuttur (Rowgani ve Zamiri, 2007; Rowgani ve ark., 2008). Ayrica ham ve bir kısım çekirdeği alınmış zeytin posasına melas ilave edilerek hazırlanan zeytin posası silajının ruminant hayvanların yemlerinde sınırlı düzeyde kullanılabileceği belirtilmiştir (Abarghoei ve ark., 2011).

Silolanmış zeytin posasının, çoklu yem bloklarında karışım olarak (100-780 g/kg) (Hadjipanayiotou, 1996) ve/veya arpa kuru otu, arpa samanı veya kesif yem karmalarına ikame şeklinde kuzu büyütme denemelerinde (Hadjipanayiotou ve Koumas, 1996) ve laktasyondaki hayvanlarda (Hadjipanayiotou, 1999) herhangi bir olumsuz etkisi olmaksızın kullanılabileceği belirtilmiştir. $\% 20$ düzeyine kadar fermente edilmiş zeytin posası kullanımının laktasyondaki koyunlarda deneme sonu canl 1 ağıllık, günlük canlı ağırlık artışı, yem tüketimi ve süt verimine olumsuz bir etkisi olmaksızın kullanılabileceği bildirilmiştir. (Christodoulou ve ark., 2008; Tajori, 2009).

Zeytin posası silajına katkı maddesi olarak mısır, buğday kepeği ve melas ilavesinin lif fraksiyonlarının sindirimini, silaj kuru madde tüketimini ve oğlakların performansını artırdığı görülmüsştür (Sleiman ve ark., 2006). Tavuk gübresi, zeytin posası ve buğday kepeği (45:45:10) kullanılarak yapılan silajin, koyunların sağlığına olumsuz bir etkisi olmaksızın kesif yeme ikame olarak rasyonda başarılı bir şekilde kullanılabileceği bildirilmiştir (Kayouli ve ark., 1993). Yine narenciye (portakal) pulpu, zeytin posası ve parçalanmış buğday samanı silajı $(65 / 30 / 5)$ ve $\% 40$ ticari konsantre yem içeren karmanın kuzuların beslenmelerinde (Cappara ve ark., 2003) ve yulaf samanı ve ticari konsantre yem $(40 / 60)$ ve narenciye (portakal) pulpu, zeytin posası ve buğday samanından $65 / 30 / 5$ ve $55 / 40 / 5$ oranında oluşturulan silajin ticari konsantre yemle $60 / 40$ oranında verilmesinin kuzularda et kalitesi üzerine herhangi bir olumsuz etkisinin olmadığı bildirilmiştir.(Foti ve ark., 2003). Buğday kepeği, zeytin posası ve turunçgiller posasından oluşan silaj karışımları (Zaza, 2008) ve zeytin posası, kaktüs ve buğday kepeğinden oluşan silaj karışımlarının (Abidi ve ark., 2010) kolay teknikle üretilen ve iyi kalitede bir yem kaynağı olarak kuzuların rasyonlarında kullanılabileceği belirlenmiştir.

$\mathrm{Bu}$ çalışmada, mısır silajina farklı oranlarda zeytin posas1 ilavesinin silaj kalitesi üzerine etkileri araştırılmıştır.

\section{Materyal ve Metot}

Silo Materyali ve Silolama Dönemi

Araştırmada ana materyal olarak kullanılan mısır hasıl1, yetiştiriciden üretim sezonunda ikinci ürün olarak ekili alanlardan hamur olum döneminde hasat edilerek temin edilmiştir. Araştırmada kullanılan yaş zeytin posası ticari olarak faaliyet gösteren üç fazlı hekzan ile ekstraksiyon işleme teknolojisine sahip zeytinyağı üretim işletmesinden üretim sezonunda taze olarak temin edilmiştir. Silolamada kullanılan mısır hasılı ve zeytin posası aynı gün temin edilerek taze olarak silolama işlemi gerçekleştirilmiştir.

Laboratuvar koşullarında silolamada 5 lt'lik anaerobik plastik kavanozlar kullanılmıştır. Araştırmada zeytin posası misır hasılına $\% 0,20$ ve 40 oranında katılarak üç farklı silaj grubu ve her grupta 3 tekerrürden oluşturulmuştur. Plastik kavanozlar belirtilen oranlarda mısır hasılı ve zeytin posası ile doldurulduktan sonra ağzı PVC kapak ile sıkıca kapatılmıştır. Silolama dönemi 56 gün devam etmiştir.

\section{Kimyasal Analizler}

Elli altı gün sonunda kavanozlar açılmış ve silaj örneklerinde açıldığı andaki pH değerleri belirlenmiştir. Silaj örneklerinde $\mathrm{pH}$ değerlerinin belirlenmesi amaciyla $25 \mathrm{~g}$ silaj örneği alınmış üzerine $100 \mathrm{ml}$ saf su ilave edilmiş ve çalkalayıcı ile karıştıııldıktan sonra elde edilen sıvının pH'sı dijital pH metreyle ölçülmüştür (Polan ve ark., 1998). Yine, silajların açılmasından hemen sonra 40 g silaj örneği alınmış ve $360 \mathrm{ml}$ saf su ilave edilerek en az 5 dakika çalkalanmıştır. Çalkama işlemi sonrasında karışım Whatman no:1 kağıdından süzülmüş ve elde edilen süzükten $100 \mathrm{ml}$ alınarak Kjeldahl distilasyon yöntemiyle $\mathrm{NH}_{3}-\mathrm{N}$ tayini yapılmıştır. Bununla birlikte, aynı süzükten $2 \mathrm{ml}$ alınmış, 30 dakika 14.000 devir/dakika santrifüj edilmiş ve $1 / 10$ seyreltilerek uçucu yağ asitleri [asetik asit (AA), propiyonik asit (PA) ve bütirik asit (BA)] ve laktik asit (LA) miktarları belirlenmiştir (Dubois ve ark., 1956; Leventini ve ark., 1990). Silajların aerobik stabilite testlerinde Ashbell ve ark. (1991) tarafından geliştirilen yöntem kullanılmıştır.

Yine silajların açım gününde kitleyi temsil edecek şekilde alınan silaj örnekleri sirkülasyonlu etüvde $60^{\circ} \mathrm{C}$ 'de 
48 saat kurutmaya tabi tutulduktan sonra kuru madde (KM) değerleri belirlenmiştir (AOAC, 1999). Kurutulan örnekler, $1 \mathrm{~mm}$ elek çapında öğütülmüş ve AOAC (1999)'da belirtilen şekilde $550^{\circ} \mathrm{C}$ 'de 4 saat kül firınında yakılarak örneklerin ham kül (HK), OM=KM-HK formülüyle organik madde (OM) içeriği ve Kjeldahl yöntemiyle de ham protein (HP) içerikleri \% kuru madde esasına göre saptanmıştır. Silaj örneklerine ait ham selüloz (HS), nötral deterjan fiber (NDF), asit deterjan fiber (ADF) ve asit deterjan lignin (ADL) içeriği belirlemede kullanılan analizler, Van Soest ve ark.(1982)'nın bildirdiği şekilde Fiber Analyzer (Ankom Technology Corp. Fairport, NY, USA) cihazı kullanılarak yapılmıştır (Ankom, 1998). Silaj örneklerinin ham yă̆ (HY) içerikleri petrol eteri ile ekstraksiyon yöntemine göre yine Ankom cihazında belirlenmiştir.

\section{In vitro Sindirilebilirlik Analizleri}

Araştırmada silaj gruplarının in vitro kuru madde $\left(\mathrm{IVS}_{\mathrm{KM}}\right.$ ), organik madde (IVS $\mathrm{OM}_{\mathrm{O}}$ ) ve NDF (IVS $\left.\mathrm{IDF}_{\mathrm{NDF}}\right)$ sindirilebilirlik içeriklerini belirlemek amacıyla Tilley ve Terry (1963)'nin bildirdiği yöntem uygulanarak Ankom cihazıyla tespit edilmiştir. (Ankom, 1998).

\section{Istatistiki Analizler}

Sonuçlar SPSS paket programda ONE-WAY ANOVA prosedürüne göre analiz edilmiş olup, grupların farklılıkları için Duncan Çoklu Karşılaştırma Testi uygulanmıştır (SPSS, 1999).

\section{Bulgular ve Tartışma}

\section{Ham Besin Maddeleri İçerikleri}

Araştırmada kullanılan taze zeytin posası ve misır hasılının besin madde içerikleri Tablo 1'de, 56 gün sonunda elde edilen misır hasıl1-zeytin posası karışımlarından oluşan silajlara ait besin madde içerikleri ise Tablo 2'de verilmiştir. Elde edilen bulgulara göre, silajların NDF ve HK içerikleri bakımından görülen farklılıklar istatistiki olarak önemli bulunmamıştır $(\mathrm{P}>0,05)$. Bu durum, saf misır silajı ve saf zeytin posasının NDF içeriklerinin birbirine yakın olmasından kaynaklanmış olabilir. Elde edilen bu sonuç, bir yan ürün olarak zeytin posasının mısır silajı içerisine \%40 oranında katılmasının NDF içeriği açısından bir olumsuzluk oluşturmayacağını göstermektedir. Silajların NDF içerikleri bakımından görülen farklılıkların önemli olmaması, silaj fermentasyonunun bitki hücre duvarı bileşenleri üzerindeki etkisinin sınırlı olmasından kaynaklanabilir. Misır hasılına zeytin posası ilave edilen gruplarda KM, OM, HY, ADF ve ADL içerikleri önemli düzeyde artmıştır $(\mathrm{P}<0,01)$. Mısır hasılına farklı düzeylerde zeytin posası ilavesiyle HY düzeyi artmış ve gruplar arasındaki farklılıklar istatistiki olarak önemli bulunmuştur $(\mathrm{P}<0,01)$. Misır hasılı silajlarında zeytinyağ sanayii yan ürünü olan zeytin posasının misır hasıllarındaki karışım oranları arttıkça yüksek yağ içeriği nedeniyle HY oranının arttığı görülmüştür. Bu bulgular, $\% 100$ zeytin posası ila silolama yapan Abarghoei ve ark. (2011)'nın iki fazlı sistemden üretilen ham zeytin posası silajının \%14,1 HY içerdiğini belirtikleri çalışmayla benzerlik göstermemektedir. Bu farkl1lıkta, zeytin posası silajlarının HY değerleri üzerine zeytinin ekstraksiyon yönteminin ve çekirdeğin kısmen ayrılması suretiyle zeytinin işlenmesinin etkisinin olduğu söylenebilir. Taze zeytin posasının sahip olduğu yüksek HY, KM, OM ve ADF değerlerinin zeytin posasının misır hasılı ile silolanması ile de elde edildiği görülmüştür. Silaja zeytin posası ilavesiyle silajın HP değerinin düştüğü ve gruplar arasındaki farklılığın önemli olduğu bulunmuştur $(\mathrm{P}<0,01)$. Misır hasılı silajında HP değeri 8,27 olarak elde edilmiş ve bu oran Aksu ve ark. (2004)'nın mısır silajında HP oranını \%5,9; Şahin ve ark. (1997)'nın \%7,0 ve Bayatkouhsar ve ark. (2012)'nın \%6,09 olarak belirttikleri değerlerden daha yüksek bulunmuştur.

Tablo 1 Taze zeytin posası ve misır hasılının besin madde ve in vitro sindirilebilirlik değerleri

\begin{tabular}{l|rr}
\hline Parametreler & Taze ZP & Taze MH \\
\hline $\mathrm{KM}^{1}$ & 58,32 & 32,01 \\
$\mathrm{OM}^{2}$ & 53,29 & 25,37 \\
$\mathrm{HK}^{2}$ & 5,03 & 6,64 \\
$\mathrm{HY}^{2}$ & 11,06 & 0,93 \\
$\mathrm{HP}^{2}$ & 8,06 & 8,73 \\
$\mathrm{HS}^{2}$ & 28,02 & 27,53 \\
$\mathrm{NDF}^{2}$ & 52,86 & 53,99 \\
$\mathrm{ADF}^{2}$ & 34,72 & 31,51 \\
$\mathrm{ADL}^{2}$ & 17,50 & 27,40 \\
IVS $_{\mathrm{KM}}$ & 65,23 & 40,08 \\
IVS $_{\mathrm{OM}}$ & 63,30 & 38,17 \\
IVS $_{\mathrm{NDF}}$ & 43,50 & 30,15 \\
\hline
\end{tabular}

\section{Fermentasyon özellikleri}

Silolama dönemi sonunda açılan silajların fermentasyon özelliklerine ait değerler Tablo 3'de verilmiştir. Buna göre, silajların $\mathrm{pH}$, aerobik stabiliteleri $\left(\mathrm{CO}_{2}, \mathrm{~g} / \mathrm{kg}\right)$, LA, AA ve PA içerikleri bakımından görülen farklılıkların önemli olmadığı belirlenmiştir $(\mathrm{P}>0,05)$. Zeytin posası ilave edilen gruplarda PA saptanmamıştır. Araştırma silajlarında amonyak azotu ve BA içeriğine rastlanılmamıştır. Silajların kalitesini, fermentasyon esnasında oluşan $\mathrm{pH}$, amonyak azot ve organik asitlerin miktarı ve kompozisyonları belirlemektedir. Fermentasyonun erken aşamasında ortam pH'sındaki düşüş hızı iyi bir silaj elde etmek için büyük önem taşımaktadır. Silolanan materyalin pH'sının olabildiğince çabuk bir şekilde 4,2 ve daha aşağıya düşmesi arzu edilmektedir. (Ergün ve ark., 2004). Amonyak azotunun kaliteli bir silajda $80 \mathrm{~g} / \mathrm{kg}$ toplam N'den düşük olması gerektiği bildirilmektedir (Petterson, 1988). Ayrıca McDonald ve ark. (1991), silajlarda bulunan yüksek oranda AA içeriği nedeniyle aminoasitlerde deaminasyon gerçekleştiğini ve sonuç olarak amonyak seviyesinin yükseldiğini bildirmişlerdir. Deneme silajlarındaki zeytin posası silajlarının fermentasyon özelliklerine ait değerler istenen fermentasyon koşullarının sağlandığını göstermektedir. Nitekim zeytin posası ilaveli silajların; $\mathrm{pH}$ değerlerinin iyi bir silaj için istenilen değer aralıklarında olması, LA'in yeterli düzeyde üretilmesi, silajda istenmeyen uçucu yağ asitlerinden olan BA'in hiç bulunmaması, aerobik bozulmanın çok az düzeyde olması ve silajlarda kötü fermentasyon koşulları sonucu proteolizis aktivitesinden dolayı oluşan amonyak azotuna rastlanılmaması bu durumu desteklemektedir. Araştırmada \%100 mısır hasılından oluşan silaja ait 
aerobik stabilite değeri Filya ve ark. (2004)'nın \%100 mısır hasılından oluşan silajlarda yaptıkları çalışmada, aerobik stabilite değerlerini \%2,3; Sucu ve Filya (2006)'nın \%0,8 ve Filya (2002)'nın ise \%0,46 olarak belirttikleri değerlerle uyum içerisinde olmamıştır.

Mısır hasıl1-zeytin posası karışımlarından oluşan silajların in vitro $\mathrm{KM}$, OM ve NDF sindirilebilirlikleri incelendiğinde (Tablo 4), bu üç parametrenin de zeytin posası ilavesiyle arttığ 1 belirlenmiştir. $(\mathrm{P}<0,01) . \mathrm{Bu}$ durum zeytin posasının $\dot{I V S}_{\mathrm{OM}}$, IVS $_{\mathrm{KM}}$ ve $\dot{I V S}_{\mathrm{NDF}}$ sindirilebilirlik değerlerinin mısır hasılından yüksek olmasına bağlanabilir (Tablo 1). Nitekim misır hasılına zeytin posasının artan düzeylerinin ilavesiyle IVS ${ }_{\mathrm{OM}}$, IVS $_{\mathrm{KM}}$ ve İVS $\mathrm{NDF}_{\mathrm{N}}$ sindirilebilirlik değerlerinin de arttığı görülmektedir.

Silolamada kullanılan bitkisel materyalin biçim dönemi silajların in vitro besin madde sindirilebilirlik değerlerini etkilemektedir. Çünkü bitki materyalinin biçiminin gecikmesi halinde bitkinin kuru madde içeriği silolama için uygun olmayan düzeyde artmakta ve dolayısıyla silajların suda çözünebilir karbonhidrat oranı ve organik maddelerin sindirilebilirliği düşmektedir. Mısırın gerek erken gerekse geç biçilerek silolanması halinde her iki durumda da fermentasyon etkinliği düşmektedir. Araştırmadan elde edilen KM, OM ve düşük $\mathrm{pH}$ değerlerine ait bulgular, mısır hasıllarının silolama için en uygun dönemde biçildiğini göstermektedir.

Tablo 2 Mısır hasıl1-zeytin posası karışımlarından oluşan silajlara ait ham besin madde içerikleri

\begin{tabular}{l|rrrrr}
\hline \multicolumn{1}{c|}{ Parametreler } & Kontrol & \% 20 ZP* & $\% 40 \mathrm{ZP}$ & \multicolumn{1}{c}{$\mathrm{X}$} \\
\hline $\mathrm{KM}^{1}$ & $27,48^{\mathrm{c}}$ & $32,89^{\mathrm{b}}$ & $37,81^{\mathrm{a}}$ & 32,72 & 0,0001 \\
$\mathrm{OM}^{2}$ & $17,79^{\mathrm{c}}$ & $24,27^{\mathrm{b}}$ & $29,49^{\mathrm{a}}$ & 25,06 & 0,0001 \\
$\mathrm{HK}^{2}$ & 10,26 & 8,62 & 8,32 & 8,83 & 0,06 \\
$\mathrm{HY}^{2}$ & $1,76^{\mathrm{c}}$ & $4,52^{\mathrm{b}}$ & $6,46^{\mathrm{a}}$ & 4,21 & 0,0001 \\
$\mathrm{HP}^{2}$ & $8,27^{\mathrm{a}}$ & $7,44^{\mathrm{b}}$ & $7,02^{\mathrm{b}}$ & 7,53 & 0,01 \\
$\mathrm{HS}^{2}$ & $21,55^{\mathrm{b}}$ & $24,66^{\mathrm{b}}$ & $28,81^{\mathrm{a}}$ & 24,25 & 0,01 \\
$\mathrm{NDF}^{2}$ & 47,97 & 47,24 & 50,38 & 48,45 & 0,38 \\
$\mathrm{ADF}^{2}$ & $27,11^{\mathrm{c}}$ & $29,92^{\mathrm{b}}$ & $32,38^{\mathrm{a}}$ & 29,96 & 0,001 \\
$\mathrm{ADL}^{2}$ & $2,32^{\mathrm{c}}$ & $6,53^{\mathrm{b}}$ & $9,60^{\mathrm{a}}$ & 5,04 & 0,0001 \\
\hline
\end{tabular}

${ }^{1}$ Taze materyal üzerinden $(\%),{ }^{2}$ Kuru madde üzerinden $(\% \mathrm{KM}) .{ }^{*}$ ZP: Zeytin posası, ${ }^{\text {a-c }}$ : Aynı satırda farklı harfleri taşıyan gruplar içerisindeki farklılıklar istatistiki olarak önemlidir $(\mathrm{P}<0,01)$.

Tablo 3 Mısır hasılı-zeytin posası karışımlarından oluşan silajların fermentasyon özelliklerine ait değerler

\begin{tabular}{l|rrrrr}
\hline \multicolumn{1}{c}{ Parametreler } & Kontrol & \% 20 ZP & \% 40 ZP & X & P \\
\hline $\mathrm{pH}$ & 3,66 & 3,71 & 3,72 & 3,70 & 0,37 \\
$\mathrm{NH}_{3}-\mathrm{N}$ & 0 & 0 & 0 & & \\
$\mathrm{CO}_{2}, \mathrm{~g} / \mathrm{kg}$ & 0,008 & 0,006 & 0,009 & 0,008 & 0,77 \\
$\mathrm{LA}, \mathrm{Mm} / \mathrm{L}$ & 1,10 & 0,62 & 0,76 & 0,82 & 0,74 \\
$\mathrm{AA}, \mathrm{Mm} / \mathrm{L}$ & 0,15 & 0,05 & 0,16 & 0,10 & 0,05 \\
$\mathrm{PA}, \mathrm{Mm} / \mathrm{L}$ & 0,007 & 0 & 0 & 0,001 & 0,30 \\
$\mathrm{BA}, \mathrm{Mm} / \mathrm{L}$ & 0 & 0 & 0 & & \\
\hline
\end{tabular}

Tablo 4 Mısır hasıl1-zeytin posası karışımlarından oluşan silajların in vitro sindirilebilirlik değerleri

\begin{tabular}{l|rrrrr}
\hline \multicolumn{1}{c|}{ Parametreler } & Kontrol & $\% 20 \mathrm{ZP}$ & $\% 40 \mathrm{ZP}$ & $\mathrm{X}$ & $\mathrm{P}$ \\
\hline IVS $_{\mathrm{KM}}$ & $41,73^{\mathrm{c}}$ & $48,58^{\mathrm{b}}$ & $57,92^{\mathrm{a}}$ & 48,91 & 0,0001 \\
IVS $_{\mathrm{OM}}$ & $40,21^{\mathrm{c}}$ & $46,99^{\mathrm{b}}$ & $56,89^{\mathrm{a}}$ & 46,26 & 0,0001 \\
IVS $_{\mathrm{NDF}}$ & $29,44^{\mathrm{c}}$ & $34,11^{\mathrm{b}}$ & $38,79^{\mathrm{a}}$ & 33,45 & 0,0001 \\
\hline
\end{tabular}

${ }^{a-c}:$ Aynı satırda farklı harfleri taşıyan gruplar içerisindeki farklılıklar istatistiki olarak önemlidir $(\mathrm{P}<0,01)$.

\section{Sonuç}

Son yıllarda dünya nüfusunun hızlı artmasına bağlı olarak hayvansal gıda ihtiyacının artması yem kaynağı açığını da gündeme getirmiştir. İşlenmiş gıda sektöründe kimi zaman atık, kimi zaman ise yan ürün olarak adlandırdığımız pek çok ürün yeni (alternatif) yem kaynağ1 olarak kullanılabilmektedir. $\mathrm{Bu}$ bağlamda dikkatle irdelenmesi ve değerlendirilmesi gereken ürünlerden birisi de tarıma dayalı sanayinin hayvansal üretime yem kaynağı olarak sağlayabileceği ve önemli bir potansiyele sahip olan zeytinyağı üretimi sonrasında elde edilen zeytin posasıdır. Özellikle ruminant hayvanların beslenmesinde rahatlıkla kullanılabilecek böyle bir alternatif yem kaynağının kurutularak yakacak olarak kullanımı yerine (prina), yem sanayiine kazandırılması ile hem çevre (hava, su, toprak) kirliliği önlenmiş, hem de ucuz bir kaynak elde edilmiş olacaktır.

Araştırma bulguları göstermiştir ki, zeytin sanayinde yan ürün olarak ortaya çıkan zeytin posasının, yoğun olarak üretildiği dönemde hayvan beslemede kullanımı için uygun şartlarda saklanması gerektiği ve bu saklama koşulları içinde de en uygun koşulun sulu sanayi artığı kaba yemlerin havasız koşullarda fermente edilerek saklanan "silaj" olduğu ortaya çıkmaktadır. 


\section{Teşekkür}

$\mathrm{Bu}$ araştırma makalesi, Mustafa Kemal Üniversitesi Bilimsel Araştırma Projeleri Koordinasyon Birimi (MKÜBAP) tarafindan desteklenen 1002 D 0101 no'lu Asuman DURU'nun Doktora Tez projesinin bir kısmıdır.

\section{Kaynaklar}

Abarghoei M, Rouzbehan Y, Alipour D. 2011. Nutritive value and silage characteristics of whole and partly stoned olive cakes treated with molasses. Journal of Agricultural Science and Technology. (2011) Vol. 13: 709-716.

Abidi S, Salem HB, Nefzaoui A, Vasta V, Priolo A. 2010. Silage composed of Opuntia ficus indica f. inermis cladodes, olive cake and wheat bran as alternative feed for Barbarine lambs. The VIIth General Meeting of the FAO- ICARDA International Technical Cooperation Network on Cactus Pear \& Cochineal. Agadir, Morocco. Ocotber 17-22, 2010.

Aksu T, Baytok E, Bolat D. 2004. Effects of a bacterial silage inoculant on corn silage fermentation and nutrient digestibility. Small Ruminant Research. 55: 249-252.

Al-Jassim RAM, Awadeh FT, Abodabos A. 1997. Supplementary feeding value of urea-treated olive cake when fed to growing Awassi lambs. Animal Feed Science and Technology, 64 (2/4): 287-292.

Ankom. 1998. Procedures for fibre and in vitro analysis. Asseda http://www.ankom.com.

AOAC. 1999. Official Methods of Analysis. Association of Official Analytical Chemists, 16th Ed., Arlington VA.

Ashbell G, Weinberg ZG, Azrieli A, Hen Y, Horev B.1991. A simple system to study the aerobic deterioration of silages. Canadian Agricultural Engineering, 33: 391-393.

Bayatkouhsar J, Tahmasbi AM, Naserian AA. 2012. Effects of microbial inoculant on composition, aerobic stability, in situ ruminal degradability and in vitro gas production of corn silage. International Journal of AgriScience Vol. 2(9): $774-$ 786.

Cappara P, Foti F, Cilione C, Scerra M, Vottari G, Chies L. 2003. Olive cake, citrus pulp and wheat straw silage as an ingredient in lamb diets:1. Effects on growth and carcass characteristics. Italian Journal of Animal Science. Vol. 2 (Suppl. 1): 488-490

Christodoulou V, Bampidis VA, Israilides CJ, Robinson PH, Giouzelyiannis A, Vlyssides A. 2008. Nutritional value of fermented olive wastes in growing lamb rations. Animal Feed Science and Technology. 141: 375-383

Dubois M, Gilles KA, Hamilton JK, Rebbers PA, Smith. F.1956. Colorimetric method for determination of sugars and related substances. Analytical Chemistry. 28: 350-356.

Ergün A, Çolpan İ, Yıldız G, Küçükersan S, Tuncer ŞD, Yalçın S, Küçükersan MK, Şehu A. 2004. Yemler ve Yem Hijyeni ve Teknolojisi. Pozitif Yayınları. 2. Bask1, 69-102, Ankara.

Filya İ. 2002. Laktik asit bakteri inokulantlarının misır ve sorgum silajlarının fermantasyon, aerobik stabilite ve in situ rumen parçalanabilirlik özellikleri üzerine etkileri. Turkish Journal of Veterinary and Animal Sciences. 26: 815-823.

Filya İ, Sucu E, Hanoğlu H. 2004. Misır silajına katılan ürenin silaj fermantasyonu, aerobik stabilite, rumen parçalanabilirliği ve kuzuların besi performansı üzerine etkileri. Tarım Bilimleri Dergisi 10(3): 258-262.

Filya İ, Hanoğlu H, Canbolat Ö, Sucu E. 2006. Kurutulmuş pirinanın yem değeri ve kuzu besisinde kullanılma olanakları üzerinde araştırmalar. 1. Yem Değerinin in situ Yöntemle Belirlenmesi. Uludağ Üniversitesi Ziraat Fakültesi Dergisi 20(1): 1-12.
Foti F, Caparra P, Giuffrida G, Scerra M, Chies L. 2003. Olive cake, citrus pulp and wheat straw silage as an ingredient in lamb diets: 2. Effects on meat quality. Italian Journal of Animal Science. Vol. 2 (Suppl. 1): 491-493

Hadjipanayiotou M. 1996. Urea blocks without molasses made of a variety of by-products and binders. Livestock Research for Rural Development. 8: 4.

Hadjipanayiotou M, Koumas A.1996. Performance of sheep and goats on olive cake silages. Technical Bulletin-Cyprus Agricultural Research Institute, No.176: 10.

Hadjipanayiotou M. 1999. Feeding ensiled olive cake to lactating Chios ewes, Damascus goats and Friesian cows. Livestock Production Science. 59: 61-66.

Kayouli C, Demeyer D, Accacha M, 1993. Evaluation of poultry litter.and olive cakes as an alternative feed for ruminant production in Tunisia. Proceedings of the International Conference on Increasing Livestock Production through Utilisation of Local Resources. October 18-22, 1993 Beijing, China. pp $420-440$.

Keser O, Bilal T. 2010. Zeytin sanayi yan ürünlerinin hayvan beslemede kullanım olanakları. Hayvansal Üretim, 51(1): 64-72

McDonald P, Henderson AR, Herson SJE. 1991. The Biochemistry of Silage, 2nd edition. Chalcombe Publication, Marlow, UK.

Leventini MW, Hunt CW, Roffler RE, Casebolt DG. 1990. Effects of dietary levels of barley-based supplements and ruminal buffer on digestion and growth by beef cattle. Journal of Animal Science 68: 4334-4344.

Nefzaoui A. 1991. Nutritive value of combined laying hen excreta and olive cake silages. II. Ingested quantities, digestibility, nitrogen retention and particle flow rate in lambs. Annales De Zootechnie. 40: 113-123.

Nefzaoui A, Vanbelle M. 1986. Effects of feeding alkali-treated olive cake on intake, digestibility and Rumen liquor parameters. Animal Feed Science and Technology, 14: 139149.

Özen N, Kırkpınar F, Özdoğan M, Ertürk MM, Yurtman IYY. 2005. Hayvan Besleme. http://www.zmo.org.tr/etkinlikler/ 6tk05/037nihatozen.pdf. (Erişim: 13.10.2005)

Petterson K. 1988. Ensiling of forages: factors affecting silage fermantation and quality, Sveriges Lantbruksuniversitet, 46 p, Uppsala.

Polan CE, Stive DE, Garrett JL. 1998. Protein preservation and ruminal degradation of ensiled forage treated with heat, formic acid, ammonia, or microbial inoculant, Journal of Dairy Science, 81: 765-776.

Rowgani E, Zamiri MJ. 2007. Effects of additives on chemical composition, degradability coefficients and ruminalintestinal disappearance of dry matter and crude protein of laboratory ensiled olive cake Iranian Journal of Veterinary Research, University of Shiraz, Vol. 8, No. 1, Ser. No. 18

Rowgani E, Zamiri MJ, Seradj AR. 2008. The chemical composition, rumen degradability, in vitro gas production, energy content and digestibility of olive cake ensiled with additives. Iranian Journal of Veterinary Research, 9, 3 (24): 213-221

Sleiman FT, Issa RE, Ibrahim SH, Uwayjan MG, Hamadeh SK, Toufeili I, Farran MT. 2006. Apparent digestibility, voluntary feed intake and performance of goat kids fed olive cake ensiled with different feedstuffs. Journal of Animal Science. Vol. 84, Suppl.1/Journal of Dairy Science, Vol. 89: Suppl. 1.

SPSS. 1999. SPSS for Windows Release 10.01. SPSS Incorporation. 1999.

Sucu E, Filya İ. 2006. Effects of homofermentative lactic acid bacterial inoculants on the fermentation and aerobic stability characteristics of low dry matter corn silages. Turk Journal of Veterinary Animal Science 30: 83-88. 
Şahin K, Çelik S, Güler T, Şahin N, Çerçi İH. 1997. Silaj katkı maddelerinin silolama sirasinda ve silajlarda fermentasyon ürünleri ile mikroorganizmik değişim üzerine etkisi. Veteriner Bilimleri Dergisi, 13(2): 25-31.

Tajori RM. 2009. Evaluation of use of olive cake silage in sheep feeding and its affect on growth rate. Proceedings of the $2^{\text {nd }}$ Scientific Conference of Animal Wealth Research in the Middle East and North Africa, Cairo International Convention Center, 24-26 October, 2009 pp. 441-449.

Tilley JMA, Terry RA. 1963. A two-stage technique for the invitro digestion of forage crops. Journal of the British Grassland Society.18: 104-111.
Van Soest PJ. 1982. Analytical systems for evaluation of feeds. In: P. J. Van Soest (Editor), Nutritional Ecology of the Ruminant. Cornell University Press. Chapter 6, pp. 75-94. Ithaca, NY.

Weinberg ZG, Chen Y, Weinberg P. 2008. Ensiling olive cake with and without molasses for ruminant feding. Bioresource Technology. 99: 1526-1529.

Zaza AIA. 2008. Performance of Awassi Lambs Fed Citrus Pulp and Olive Cake Silage. An-Najah National University Faculty of Graduate Studies. 